\title{
Short term dimensional bony changes following teeth extraction in the esthetic zone and the use of PRF as a sole grafting material: Randomized controlled trial
} Article

\author{
Moustafa Mohamed Taha
}

Department of Oral and Maxillofacial Surgery, Faculty of Dentistry, Ain Shams

University, Cairo, Egypt

\begin{abstract}
Background: Bone loss after teeth extraction is a repeated observation in dental practice. Many bio materials were used in alveolar socket augmentation including platelet rich fibrin (PRF) to decrease bone loss.

Purpose: The aim of this study was to investigate the effect of PRF when used as a sole grafting material on the ordinary dimensional bony changes following teeth extraction in the aesthetic zone.

Patients and Methods: 42 fresh extraction sockets in 27 patients were included in this study. Subjects were randomly allocated into 3 groups. Study group included sockets augmented with PRF, second group included sockets augmented with xenograft and the third negative control group included patients were extraction was done with no augmentation. Subjects were assessed radiographically after extraction and before implant placement at 3 and 6 months post extraction using CBCT superimposition to assess horizontal and vertical bone loss.

Results: The amounts of horizontal and vertical bone loss were significantly higher at 3 and 6 months in PRF group when compared to xenograft group. PRF as a socket grafting has no additive effect on decreasing bone resorption in the short term period after teeth extraction in the esthetic zone.
\end{abstract}

Key Words: Extraction, PRF, socket augmentation.

Received: 01 December 2019, Accepted: 14 December 2019.

Corresponding Author: Moustafa Mohamed Taha, Department of Oral and Maxillofacial Surgery, Faculty of Dentistry, Ain Shams University, Cairo, Egypt, Tel.: +201001686562, E-mail: moustafataha@asfd.asu.edu.eg.

ISSN: 2090-097X, April 2019, Vol. 10, No. 2

\section{INTRODUCTION}

Tooth extraction, in general, had been always indicated in dental practice for a myriad of reasons, however, the restoration of the extracted site using dental implants was always the question particularly when bone loss occurs. Loss of alveolar ridge height and width can be attributed to a number of factors such as, traumatic extraction, dentoalveolar trauma, presence of periapical pathosis or periodontal disease $\mathrm{e}^{[1,2] \text {. }}$

Schropp et al, performed a prospective study to evaluate the alveolar ridge resorption following extractions in a one-year interval and he found that $50 \%$ of the ridge was reduced from its original volume ${ }^{[3]}$. Furthermore, long standing non-restored extracted sites are usually subjected to atrophy because of the loss of bundle bone which deprives the bone from the nutritive support that is provided by the periodontal ligaments vasculature ${ }^{[4,5]}$.

Consequently, this considerable bone loss particularly in the esthetic zone, would not allow for proper implant placement in a proper position and angulation which would compromise esthetics, phonetics, and functional demands of the patient. In order to prevent these problems, alveolar ridge preservation was advocated by some surgeons as an easy step which may decrease significantly the bone loss following dental extractions ${ }^{[6]}$.
There are many techniques used to augment dental sockets which usually vary in two main areas, the space fillers and how to cover the graft. The space fillers used include bovine hydroxyapatite, alloplastic bone graft materials and allograft. Some researchers use free gingival grafts to cover the graft while others use synthetic collagen based resorbable materials ${ }^{[7-10]}$.

The use of Choukroun's platelet concentrates was suggested as an aid for improving regeneration of soft and hard tissues in oral surgery in the last decade ${ }^{[1-13]}$. A new modification in a cascade of consecutive generations of platelet concentrates is platelet rich fibrin (PRF) which uses an autologous platelet suspended in a plasma volume which adds considerably to the workability of the material. had been advocated as an adjunct during socket augmentation procedures or as a sole grafting material that may improve the outcome of the ridge preservation procedures ${ }^{[14]}$.

Interestingly, three different recent systematic reviews discussed the efficacy of different grafting materials used in ridge preservation procedures and they have reached a deduction that there is no solid evidence that advocates one grafting material over another one clinically and histologically and hence the selection of the grafting material depends solely on the personal preference of surgeons rather than on trustworthy evidence ${ }^{[15-17]}$. 
Furthermore, the studies available on the dimensional changes that occur after socket augmentation using PRF are non-randomized studies and are usually long term ones with no enough data on the short term outcomes ${ }^{[18,19]}$.

The aim of this study was to describe the dimensional changes that occur to the alveolar bone at 3 and 6 months following teeth extraction in the aesthetic zone when either PRF or Bovine HA were used as socket augmentation materials.

\section{MATERIALS AND METHODS}

This study was conducted on 42 patients seeking delayed placement of dental implants after tooth extraction in the esthetic zone. Patient recruitment was carried out from Department of Oral and Maxillofacial Surgery, Ain Shams University.

Inclusion criteria were as follow: patients between 18 and 59 years old who are well and fit and seeking extraction of their anterior, non-restorable teeth. Patients below 18 years or suffering from any bone disease were excluded from this study. All patients underwent primary radiographic survey to exclude any tooth that might have a periodontal or periapical pathosis.

\section{Group allocation}

The selected individuals were allocated randomly and equally into three groups.

Group A (study group): included 14 sockets where platelet rich fibrin was placed solely after extraction and it was stabilized using 4-0 polyglactin (Vicryl) suture.

Group B: included 14 sockets where xenogeneic graft (deproteinized bovine bone mineral; Bio-Oss GeistlichPharma AG, Wolhusen, Switzerland) small particles $(0.251-\mathrm{mm})$ were used in grafting the extraction sockets. The sockets were sealed using collagen plug (CollaPlug) (Zimmer Dental, Carlsbad, CA) to protect the grafting material. The plug was stabilized by 4-0 polyglactin (Vicryl) suture.

Group $C$ : included 14 sockets where extraction was done and left to heal spontaneously without any grafting material. The soft tissue margin was approximate by figure of 8 suture using 4-0 polyglactin (Vicryl) suture.

The groups were further divided equally into two subcategories to evaluate the extraction site and the subsequent resorption rate after three months and after six months respectively.

\section{Surgical technique}

- Preparation of the patient for a traumatic extraction was done by asking them to rinse with $0.125 \%$ chlorohexidine for one minute just before extraction.

- Local anesthetic agent was administered using $2 \%$ mepivacaine with 1:20000 levonordeferin prior to extraction.

- A periotome was applied to detach subcrestal attachment apparatus, thereafter, the periotome blade was inserted into the periodontal ligament space and moved mesiodistally. Afterwards, it was pushed down to the periodontal ligament until the tooth remained attached to the alveolus only by the most apical part of the periodontal ligament and dental forceps was used to deliver the tooth.

- Then, the socket was curetted of all soft debris and granulation tissue simultaneously with irrigation using normal saline and carefully inspected to check integrity of buccal plate of bone where in case of damaged buccal bone, grafting and membrane is applied and patient would be excluded from the study.

In group A: PRF was prepared from the patient's own blood under aseptic technique using:

- Plastic syringe $(10 \mathrm{ml})$

- Vacuum sterile blood collection tubes (plain tube) $(10 \mathrm{ml})$.

- Blood centrifuge machine.

The whole blood was drawn into the vacuum plain blood collection tube and was immediately placed into the centrifuge. An appropriate balance weight was used by putting another tube filled with water to prevent machine imbalance. A centrifuge machine was adjusted to run at $3000 \mathrm{rpm}$ for 10 minutes according to Choukroun's proposed technique.119 PRF was easily separated from the red corpuscles using a sterile tweezer and scissors and then transferred into the extraction site. PRF was stabilized by suturing at the extraction site using $4-0$ polyglactin (Vicryl) suture. (Figure 1 and 2).

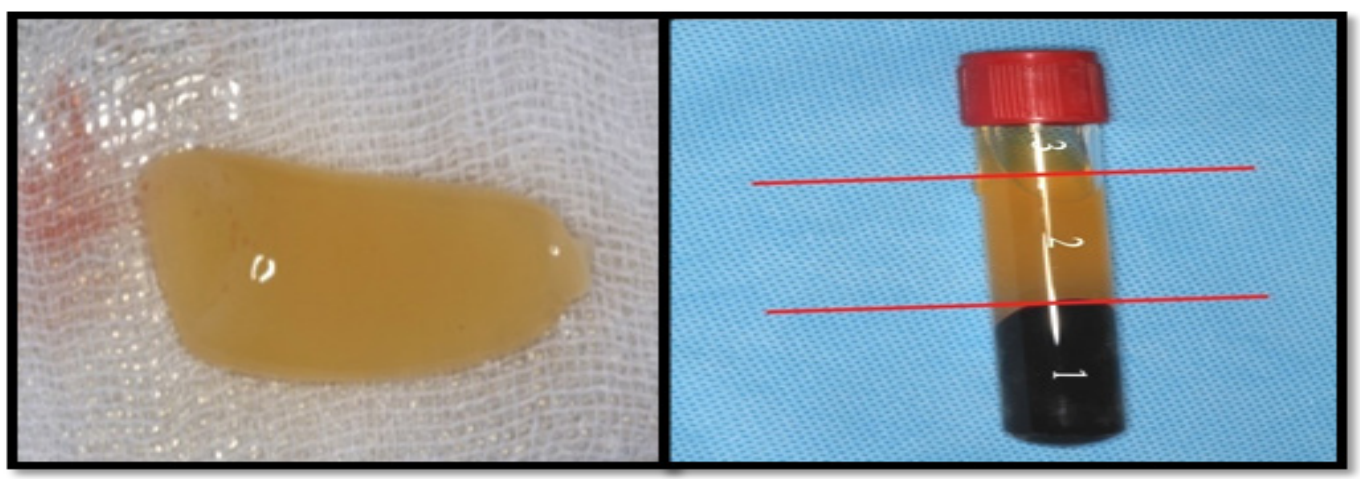

Figure 1: Macroscopic image of the PRF. 


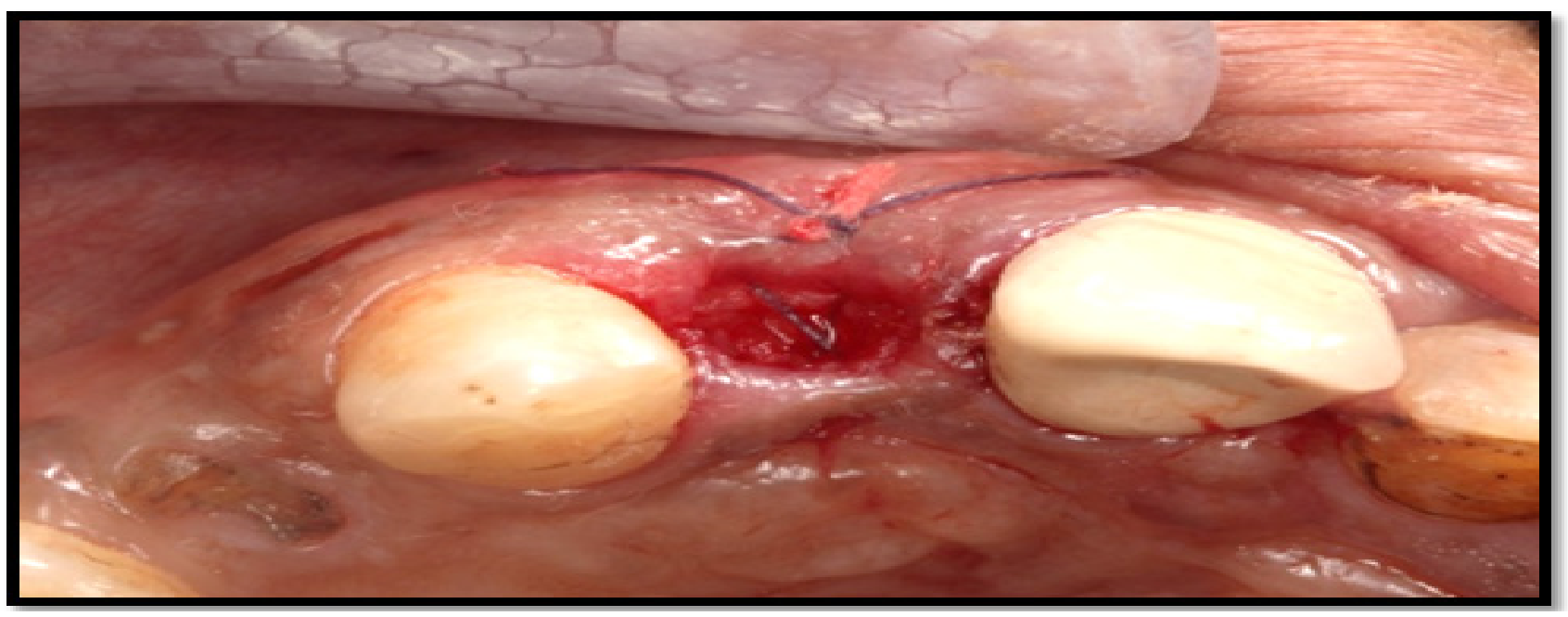

Figure 2: (Group A) PRF packed in the socket.

In group B: immediate grafting of the extraction site was done using deproteinized bovine bone mineral (BioOss GeistlichPharma AG, Wolhusen, Switzerland small particles $0.251-\mathrm{mm}$ ) till reaching the crestal level and then stabilization of the graft was performed using collagen plug and sutured by the same manner (Figure3).

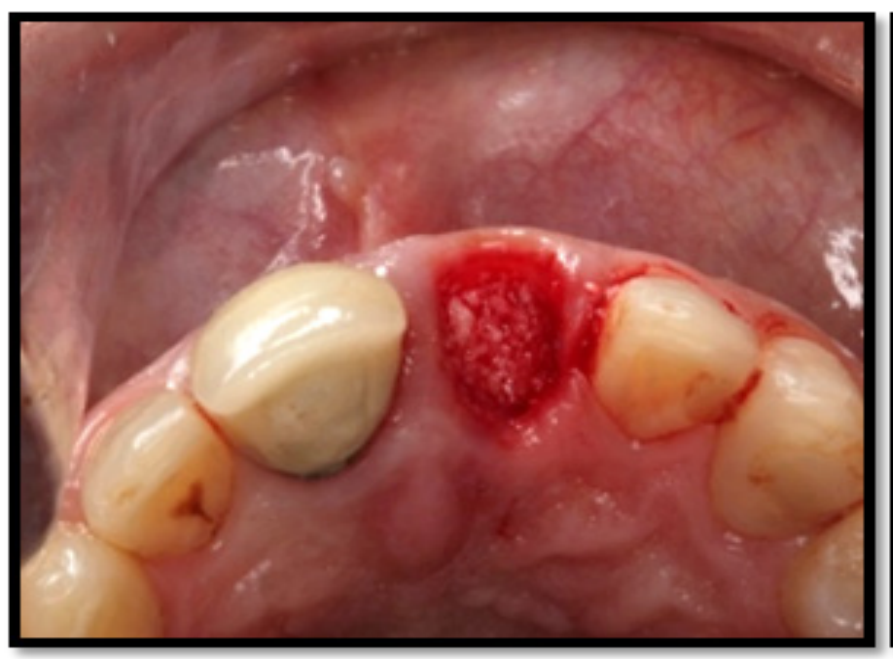

In group $\boldsymbol{C}$ : the soft tissue margins were approximated with figure of 8 suture using vicryl 4 / 0 .

\section{Postoperative follow up:}

All patients were evaluated according to the following timeline:

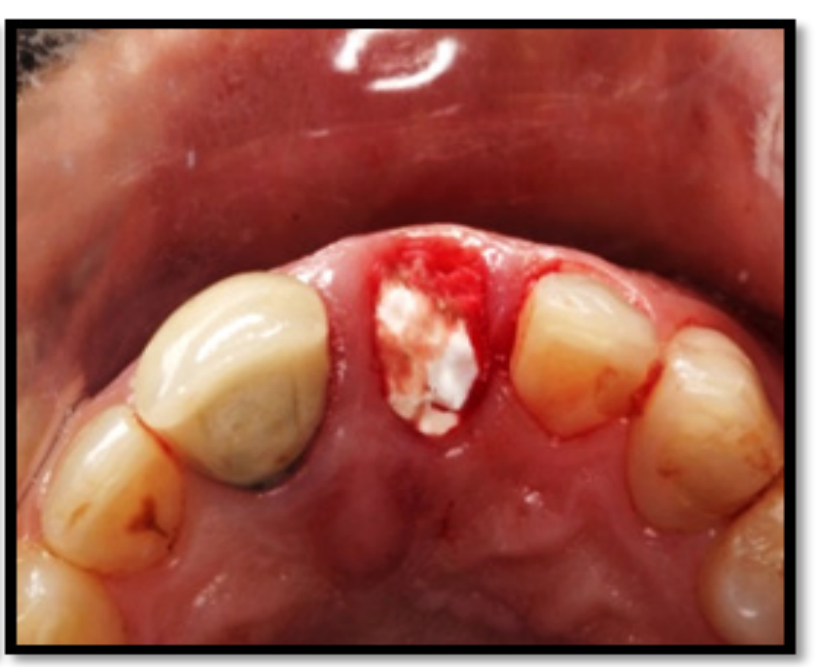

Figure 3: (Group B) Xenograft in the extraction socket to the bone level and Collagen plug in place.

\section{Two Days}

Clinical examination to check oral hygiene and presence or absence of infection and Post extraction CBCT was done.

\section{One week}

Sutures removal, soft tissue healing assessment and delivery of removable prosthesis.

\section{Three months}

Pre-implant CBCT for A3, B3,C3 followed by implant placement for A3, B3 C3.

\section{Six months}

Pre-implant CBCT for A6, B6,C6 followed by Implant placement for A6, B6, C6.

\section{Method of assessment:}

The core of measurements was performed radiographically by superimposing the immediate postextraction CBCT with three-month or six-month postextraction $\mathrm{CBCT}$ accordingly. In order to create baseline reference point, acrylic stent with radio-opaque markers was fabricated. These markers were distributed at the midbuccal and mid-palatal aspects of the tooth targeted to be extracted. 
Radiographic images was taken by CBCT (ProMax3D

Plus, Planmeca, Finland). Radiopaque markers and fixed anatomical landmarks, as maxillary sinus, adjacent teeth, palatal vault and nasal cavity were used to superimpose the post-extraction and pre-implant CBCT image (after three or six months interval) using Planmeca Romexis 3D Viewer application. The radiological measurements were taken on sagittal cut passing through two radiopaque markers and depth of extraction socket (Figure 4).

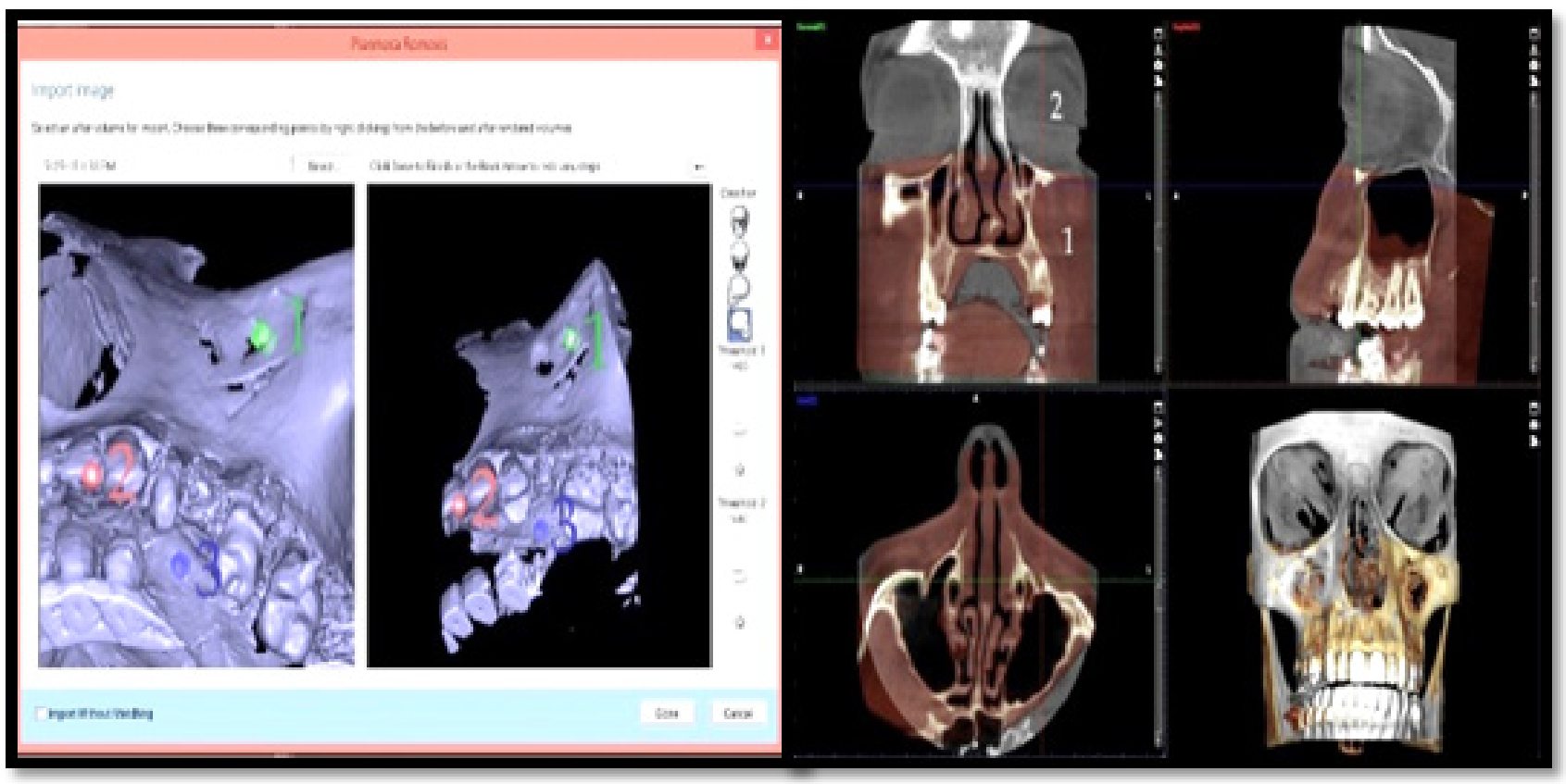

Figure 4: Manual editing of superimposition.1-Pre-implant CBCT. 2-post-extraction CBCT.

The vertical bone loss measurements were taken from differences between the crest of buccal/palatal plate in immediate post extraction images and the images taken after 3 or 6 months (Figure 5).

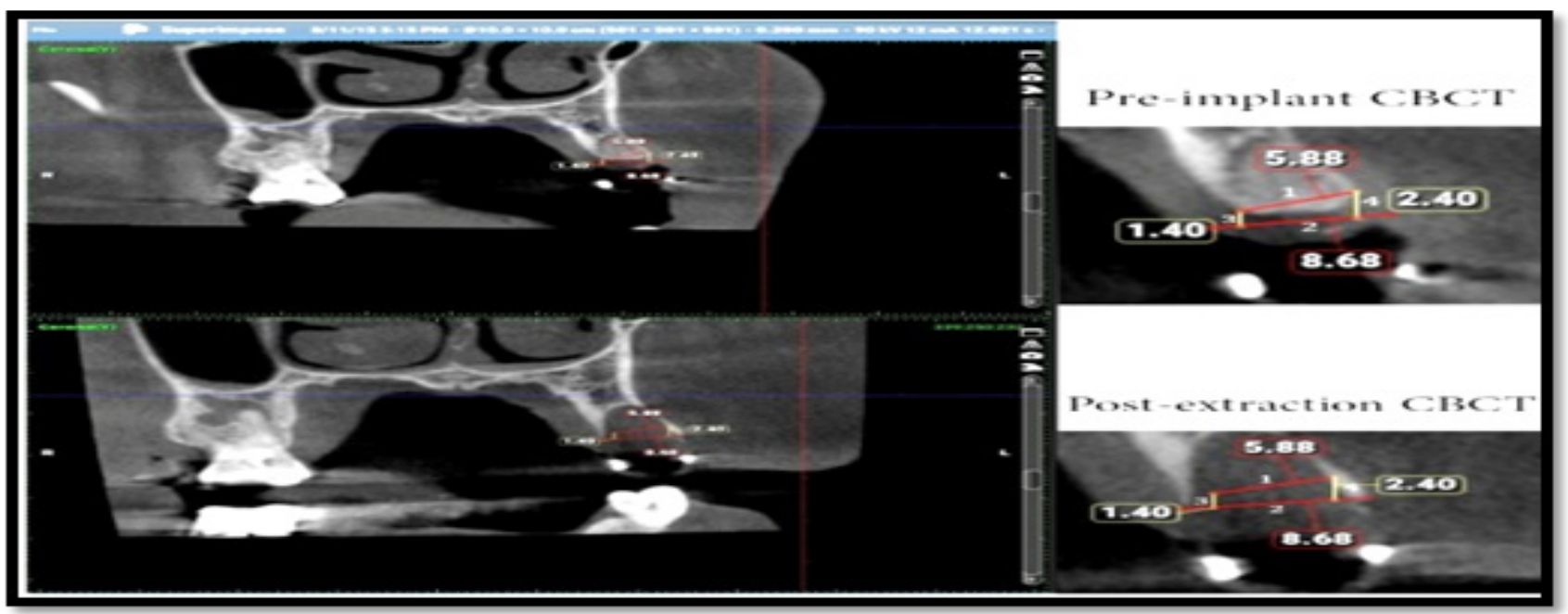

Figure 5: A print screen shot image from Romexis viewer software; showing the superimposed vertical bone loss measurements of the pre-implant СВCT (upper image) and the post extraction CBCT (lower image). The red line shows the buccolingual ridge width while the yellow line shows the vertical bone loss. 
Horizontal bone loss measurements were taken from the difference between bucco-palatal bone width in immediate post extraction images and the images taken after 3 or 6 months (Figure 6).

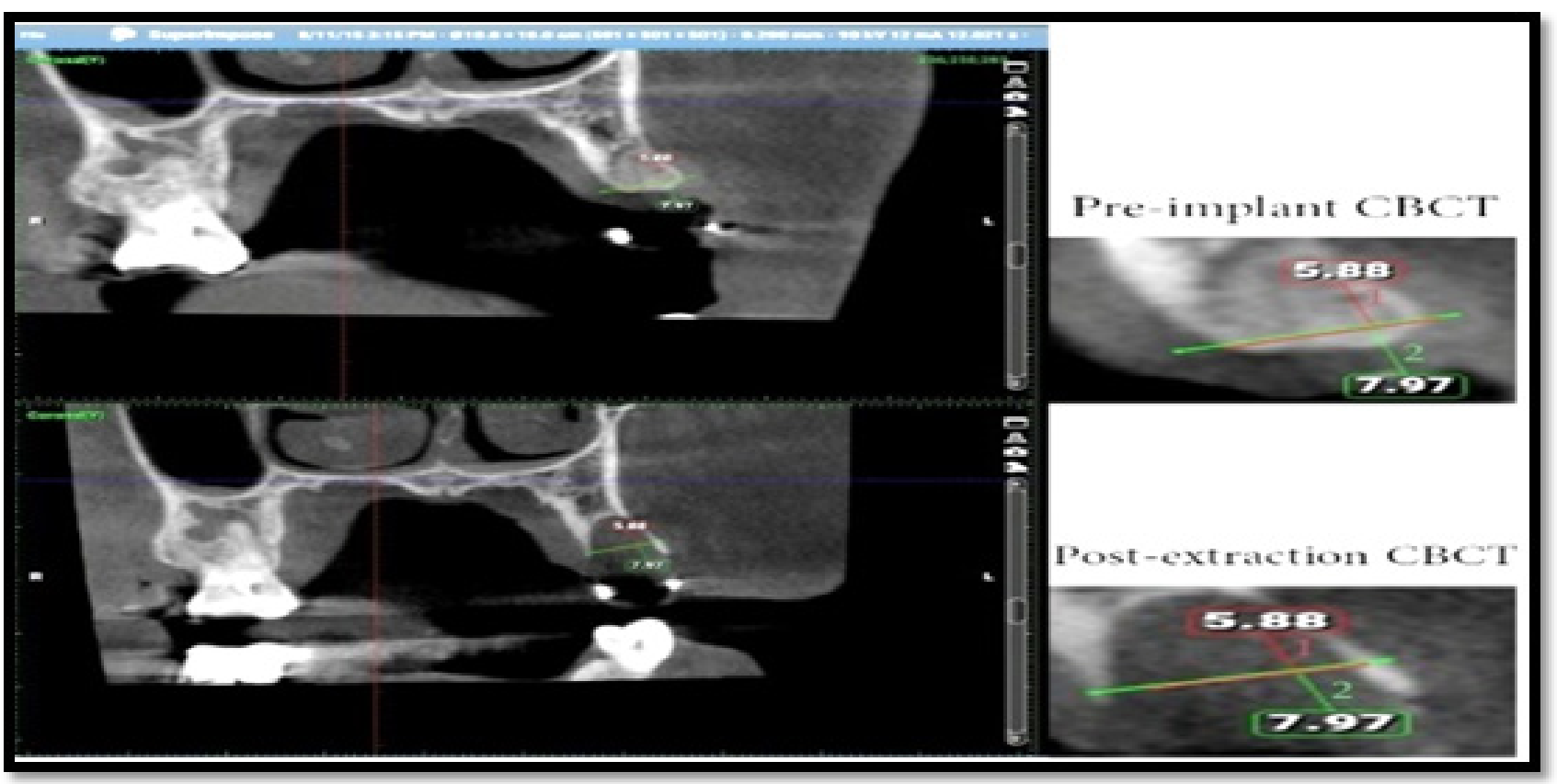

Figure 6: Print screen shot image from Romexis viewer software; showing the superimposed horizontal bone loss measurements of the preimplant CBCT (upper image) and the post extraction CBCT (lower image). The red line shows the buccolingual ridge width in pre-implant CBCT while the green line shows the buccolingual ridge width in post extraction CBCT at the same level.

\section{Statistical analysis:}

Numerical data were explored for normality by checking the data distribution, calculating the mean and median values, evaluating histograms and normality curves and using Kolmogorov-Smirnov and ShapiroWilk tests. Data were presented by mean, standard deviation (SD). Multivariate ANOVA was used to assess effect of the time, socket augmentation material and postextraction buccal plate thickness over buccal, palatal bone and horizontal bone loss. The significant level was set at $P \leq 0.05$. Statistical analysis was performed with IBM ${ }^{\circledR}$ SPSS ${ }^{\circledR}$ Statisticallyistics Version 20 for Windows. ( ${ }^{\circledR}$ IBM Corporation, NY, USA. ${ }^{\circledR}$ SPSS, Inc., an IBM Company).

\section{RESULTS}

This study included 42 fresh extraction sockets in the esthetic zone (13 first premolars, 13 second premolars,
5 canines, 5 lateral incisors and 6 central incisors). Extraction was done in 27 patients (19 females and 8 males) with age range of (2349- years), the mean age was $(37,5 \pm 5)$, affiliated to the outpatient clinic - Department of Oral and Maxillofacial Surgery - Ain shams University. The patients were randomly allocated to one of three main groups (A, B, C). Each group was subdivided according to the time of implant placement; after three months (A3, B3, and $\mathrm{C} 3$ ) and six months (A6, B6 and C6).

Comparison of vertical and horizontal bone loss to baseline after three and six months of tooth extraction (Figure 7):

Palatal vertical bone loss was $1.16 \pm 0.99$ at six months and $0.82 \pm 0.82$ after three months whereas buccal vertical bone loss was $1.64 \pm 0.87$ after six months and $1.37 \pm 1.08$ after three months. Horizontal bone loss was $1.96 \pm 0.91$ after six months and $1.19 \pm 0.8$ after three months.

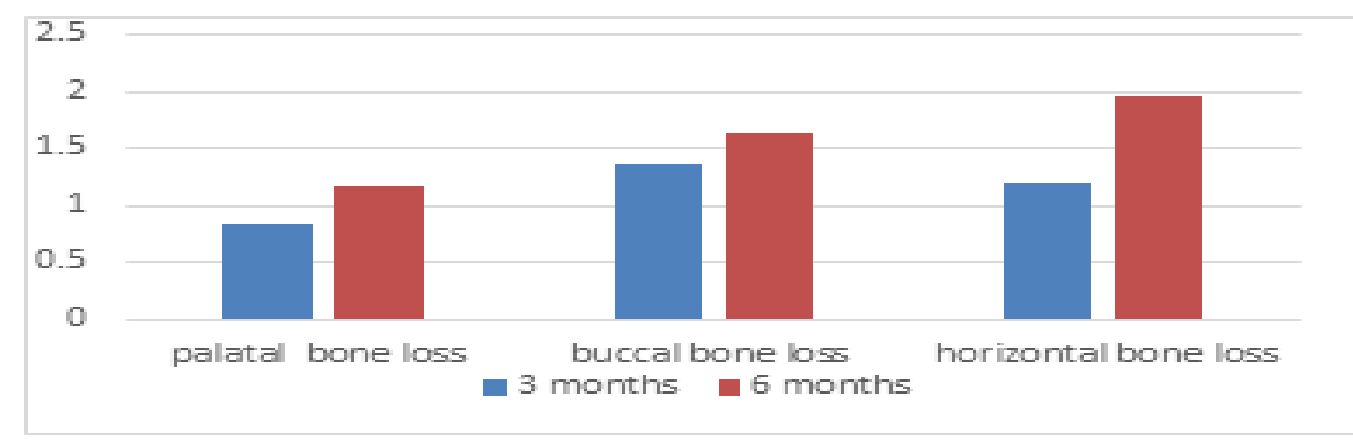

Figure 7: Bar chart showing difference in vertical and horizontal bone loss between three and six months in millimeter. 
At six months' interval, the vertical and horizontal bone loss was more pronounced when compared to that observed at three months. However, vertical bone loss is not statistically significant at 6 months when compared to the 3 months' loss. On the other hand, horizontal bone loss is statistically significant at 6 months when compared to 3 months' bone loss. ( $p$-value $\leq 0.05$ ).

Comparing palatal vertical bone loss between the three groups after three months following tooth extraction (Figure 8):

After 3 months palatal bone loss was $0.17 \pm 0.09$ in Xenograft, $1.46 \pm 0.7$ in PRF and $0.95 \pm 0.787$ in control group. Within 3 months PRF showed highest value of palatal bone loss followed by control followed by Xenograft and the difference was statistically significant as shown by post hoc test between PRF and Xenograft ( $p$-value $\leq 0.05$ ).

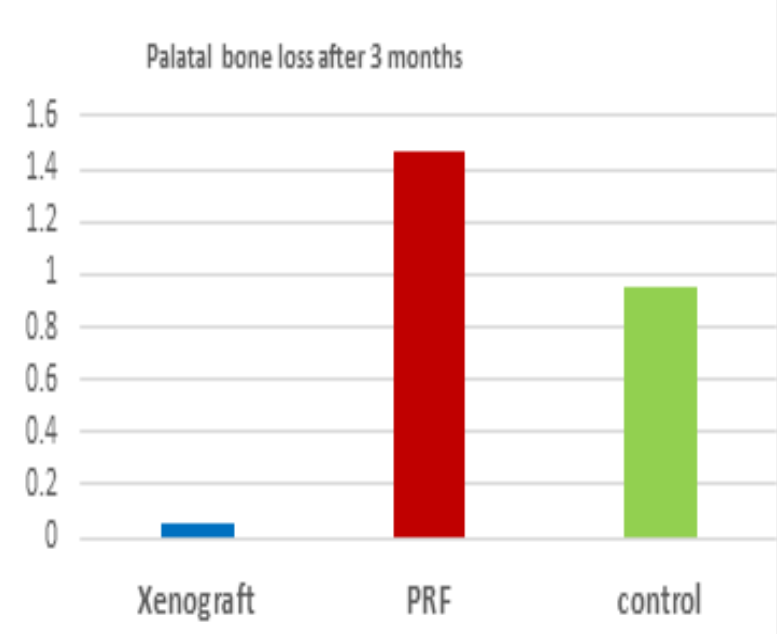

Figure 8: Bar Bar chart showing difference in palatal bone loss between the three groups after three months of tooth extraction.

Comparing buccal vertical bone loss between the three groups after 3 months following tooth extraction (Figure 9):

After three months buccal bone loss was $0,9 \pm 0.9$ in Xenograft, $2.41 \pm 0.8$ in PRF and $0.79 \pm 0.6$ in control group. Within three months PRF showed highest value of buccal bone loss followed by Xenograft followed by control and differences were statistically significant as shown by Tukey post hoc test between PRF and (Xenograft and control) group ( $p$-value $\leq 0.05$ ).

Comparing horizontal bone loss between the three groups after three months following tooth extraction (Figure 10):

After three months horizontal bone loss was $0,61 \pm 0.3$ in Xenograft, $1.48 \pm 0.9$ in PRF and 1.490.6 \pm in the control group.Within three months the control showed the highest value followed by PRF followed by Xenograft group.
At three months there were no statistically significant differences between the studied groups.

\section{Buccal bone loss after 3 months}

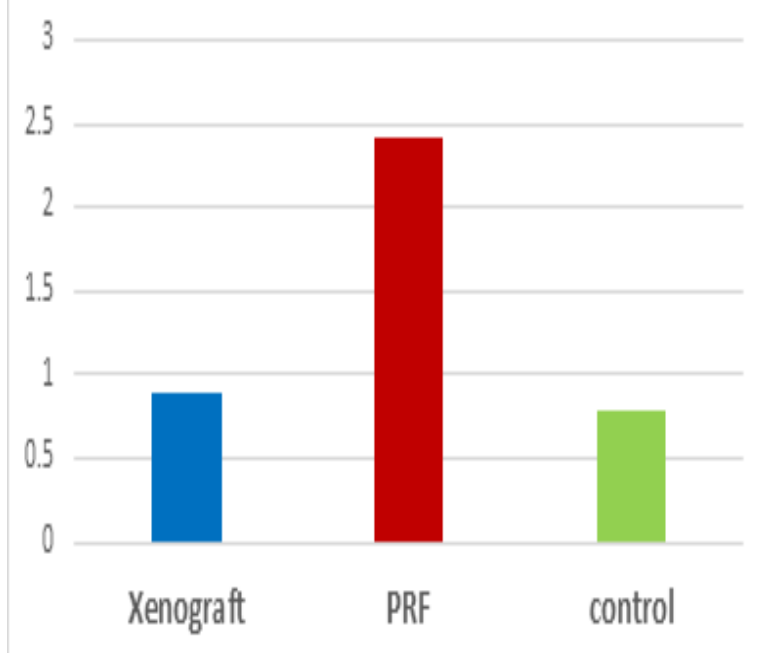

Figure 9: Bar chart showing difference in buccal bone loss between the three groups after three months of tooth extraction.

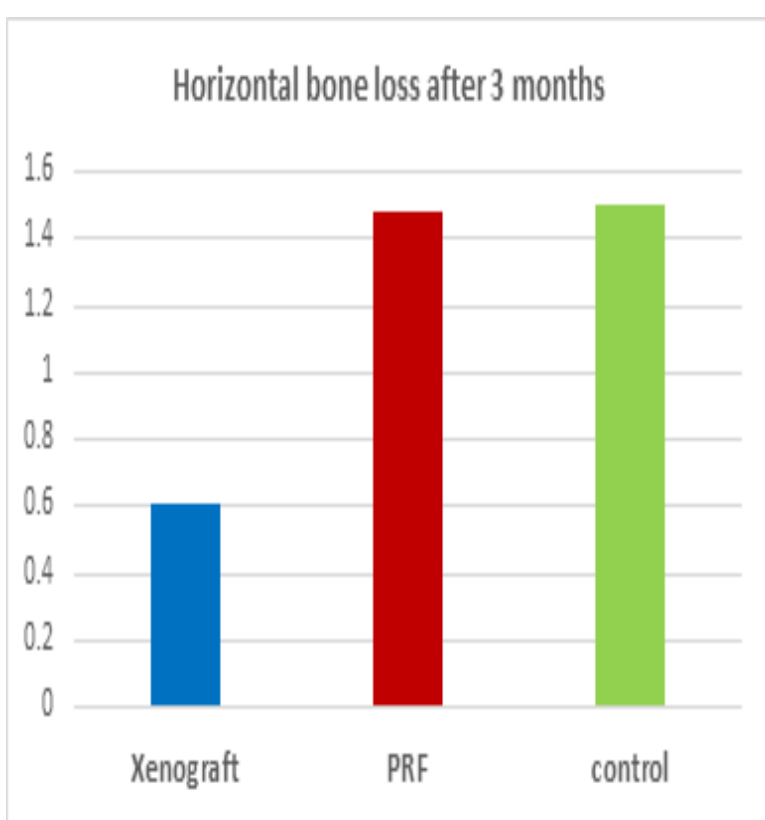

Figure 10: Bar chart showing difference in horizontal bone loss between the three groups after three months of tooth extraction.

Comparing palatal vertical bone loss between the three groups after six months following tooth extraction (Figure 11):

After 6 months palatal bone loss was $1.31 \pm 1.1$ in Xenograft, $0.96 \pm 052$ in PRF and $1.12 \pm 1.2$ in control group. Within six months xenograft showed highest value of palatal bone loss followed by control followed by PRF and Tukey post hoc test showed insignificant differences between three groups. 


\section{Palata bonelossafter 6 months}

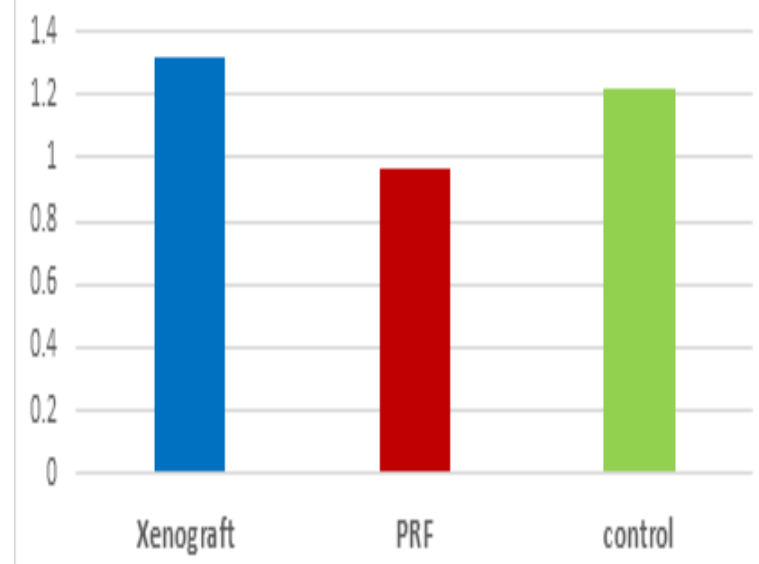

Figure 11: Bar chart showing difference in palatal bone loss between the three groups after six months of tooth extraction.

Comparing buccal vertical bone loss between three the groups after six months following tooth extraction (Figure 12):

After 6 months buccal bone loss was $1.29 \pm 1.0$ in Xenograft, $1.71 \pm 0.5$ in PRF and $1.92 \pm 0.9$ in control group.

Within six months control showed highest value of buccal bone loss followed by PRF followed by xenograft and Tukey post hoc test showed insignificant differences between three groups.

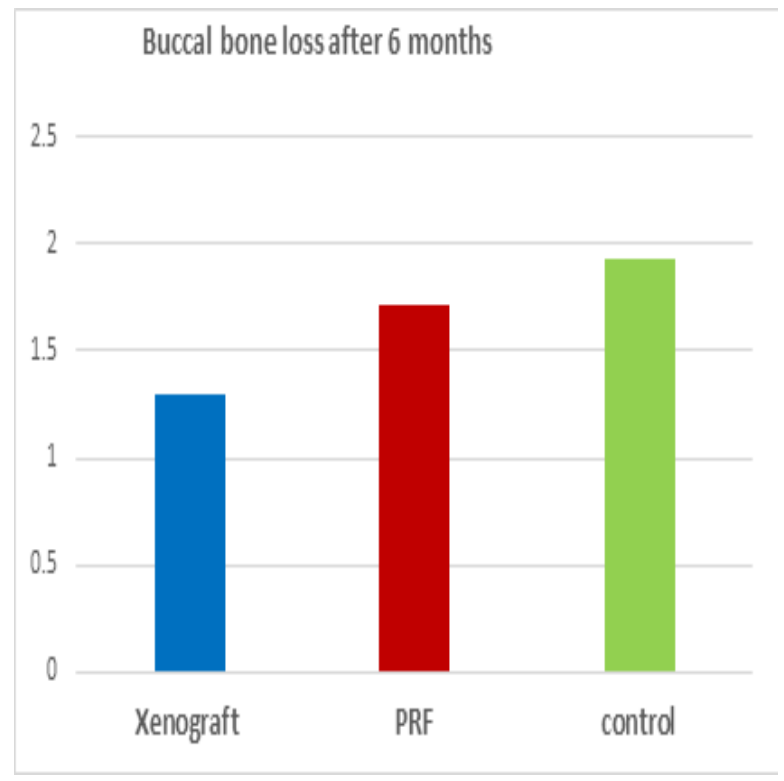

Figure 12: Bar chart showing difference in buccal bone loss between the three groups after six months of tooth extraction.
Comparing horizontal bone loss between the three groups after six months following tooth extraction (Figure 13):

After 6 months horizontal bone loss was $1.6 \pm 0.8$ in Xenograft, $2.24 \pm 1.06$ in PRF and $2.03 \pm 0.7$ in the control group. Within 6 months PRF showed highest value followed by control followed by Xenograft as regards the horizontal bone loss. At 6 months there were no statistically significant differences between the studied groups.

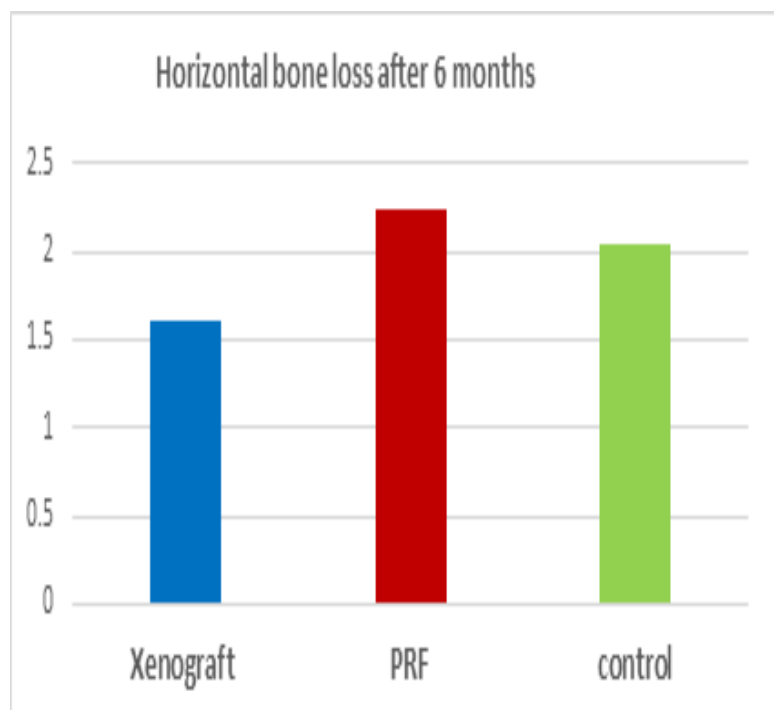

Figure 13: Bar chart showing difference in horizontal bone loss between the three groups after six months of tooth extraction.

\section{DISCUSSION}

Socket augmentation techniques are intended to lessen ridge resorption and soft tissue collapse, as well as exploit formation of bone. In systematic review conducted by Jambhekar et al. ${ }^{[20]}$ they concluded that after flapless extraction of teeth, with a minimum healing period of 12 weeks, the use of xenografts showed the best results in reducing post-extraction bone loss of socket dimensions compared to alloplasts or sockets with no grafting. In this systematic review, xenografts were the most documented material in Randomized Clinical Trials for socket grafting technique after flapless extraction. And hence, xenograft was used as positive control in this study.

Some authors consider the use of grafting material for ridge preservation as an effective scheme in reducing ridge resorption ${ }^{[21,22]}$. On the contrary, others believe the other way around arguing that intra-socket grafts may compromise the healing process of the extraction sockets ${ }^{[23,24]}$. In addition, the newly formed bone after socket augmentation in grafted sites versus non grafted ones after three months had the same volume with no added benefit according to Aroujo et al. ${ }^{[25]}$. Moreover, the 
grafted material particles occupied part of the ridge volume causing poor homogeneousness of the newly formed bone according to Becker et al. ${ }^{[23]}$. Consequently, many researchers believe that socket augmentation procedures may threaten primary stability of implants if early intervention is warranted ${ }^{[26,27]}$. That is why the concept of using autologous products was introduced as a new way of ridge preservation

Choukroun et al. introduced platelet rich fibrin (PRF) in 2001 which aims to overcome the disadvantages of other grafting material like cost, soft tissue closure and the use of non-autologous materials ${ }^{[28]}$. In fact, some authors have reported significant improvement in bone formation using $\mathrm{PRF}^{[29-34]}$ others failed to observe any advantages from the application of PRF in comparison to the standard available grafting materials ${ }^{[35-38]}$.

The main purpose of the current study was to evaluate the effect of PRF as a sole grafting material on the shortterm dimensional changes following teeth extraction in the esthetic zone

Regardless the type of socket augmentation materials, time has negative effect on bone resorption especially in horizontal bone loss ${ }^{[3,39]}$. Schropp et al. in a prospective study evaluated bony sockets with radiography on a monthly basis for one-year period. It was found that the remaining ridge was reduced to $50 \%$ of its original width in a nearly 6 month's period. More than $65 \%$ of this reduction occurred within the first 3 months ${ }^{[3]}$. Findings of the current study are consistent with the previously mentioned studies in that, the main bone resorption occurs in the first three months and in the next three months bone loss proceeded to a lesser extent.

Most of the studies conducted on socket augmentation focused on maxillary and mandibular single rooted teeth or premolars sites ${ }^{[30,31]},{ }^{[40-44]}$. The rate of bone resorption of alveolar ridge is less in maxillary $(0.1 \mathrm{~mm}$ per year $)$ than in mandibular arch $(0.4 \mathrm{~mm} \text { per year })^{[45]}$, which indicates that changes do not affect the jaws unvaryingly ${ }^{[46]}$. Anterior and premolars maxillary region was selected in the present study for a more standardization and because bone resorption in the anterior maxillary region is more critical where the natural contours of the soft and hard tissue are very important and their absence will have a negative effect on treatment outcomes ${ }^{[47]}$.

In regards to measurement of the horizontal bone loss on CBCT, the amount of the horizontal bone loss following tooth extraction is frequently greater than vertical bone loss and occurs often on the buccal side more than on the palatal side of the ridge as claimed by Lekovic et al. ${ }^{[48]}$. In the current study horizontal bone loss was measured at the preimplant CBCT level for both the immediate post-extraction and the pre implant $\mathrm{CBCT}$ after superimposition of both images. This was done to avoid the error of measuring at the post extraction crest level, which may give a false impression of gained bone width because of the bulbous shape of the socket in the premolars region. The mean bone loss at the palatal, buccal, and horizontal direction at six months interval in sockets preserved with Xenograft were $(1.31,1.29$ and $1.6 \mathrm{~mm})$ respectively, this result was close to that reported by Festa et al. ${ }^{[49]}$ in 2011 . The mean buccal and palatal vertical bone loss in our study was greater than in Festa study which may be due to the fact that he used a resorbable membrane to cover the graft and the overfilling of the defect.

Vertical bone resorption rate obtained from the current study was more pronounced in the first three months than the horizontal loss (palatal $=0.57$, buccal $=0.9$, horizontal $=0.6$ ). This was in contrast to the findings reported by Barone et al. ${ }^{[0]}$ $(0.9,1.1,1.6 \mathrm{~mm})$ which could be attributed to the difference in location of extraction sites and that clinical measurement in his study were less standardized than radiological ones in ours. Finally, the reason for the pronounced horizontal bone loss reported by Barone et $a l$. may be the horrendous efforts to primarily close the extraction sites in his study.

Since the introduction of PRF by Choukroun, several studies assessed the capabilities of this platelets concentrate on soft and hard tissue healing. Cellular proliferation of the PRF has been reported to promote the soft tissue and the hard tissue healing by releasing growth factors and cytokines. In the current study the application of the PRF in the post-extraction socket; have shown an insignificant effect in the overall bone healing. The average palatal, buccal, and horizontal bone loss were $(1.21,2.5,1.82)$ respectively which was more than the control group $(1.01,1.34,1.76)$. This difference was statistically insignificant. This finding was similar to the results that were reported by an experimental study on minipigs by Srisurang et al. ${ }^{[19]}$.

Clinical trials regarding ridge preservation are complex. The socket anatomy is an important factor because of a variety in width and height of the socket, thickness and densities of osseous plates, presence of fenestrations and dehiscence, periodontal biotype, form (single or multi rooted), and location of the socket (maxilla or mandible ${ }^{[46,51-53]}$.

Bone healing in post-extraction socket is governed by several factors including: the position of tooth in the jaw (mandible or maxilla - posterior or anterior), thickness of buccal plate at the extraction socket and the technique utilized in extraction (flap vs. flapless), while xenograft remains the most commonly used to enhance bone remodeling in extraction socket as compared to PRF which is proven to have negligible impact on the bone healing after extraction socket in the short term period.

\section{CONFLICT OF INTEREST}

There are no conflicts of interest. 


\section{REFERENCES}

1. S. E. Marcus, T. F. Drury, L. J. Brown, and G. R. Zion, "Tooth retention and tooth loss in the permanent dentition of adults: United States, 19881991-.," J. Dent. Res., vol. 75 Spec No, pp. 684-95, Feb. 1996.

2. R. A. Mecall and A. L. Rosenfeld, "Influence of residual ridge resorption patterns on fixture placement and tooth position, Part III: Presurgical assessment of ridge augmentation requirements.," Int. J. Periodontics Restorative Dent., vol. 16, no. 4, pp. 322-337, 1996.

3. L. Schropp, A. Wenzel, L. Kostopoulos, and T. Karring, "Bone healing and soft tissue contour changes following single-tooth extraction: a clinical and radiographic 12-month prospective study.," Int. J. Periodontics Restorative Dent., vol. 23, no. 4, pp. 313-323, 2003.

4. M. G. Araújo, F. Sukekava, J. L. Wennström, and J. Lindhe, "Ridge alterations following implant placement in fresh extraction sockets: an experimental study in the dog.," J. Clin. Periodontol., vol. 32, no. 6, pp. 645-52, Jun. 2005.

5. M. Araújo, E. Linder, J. Wennström, and J. Lindhe, "The influence of Bio-Oss Collagen on healing of an extraction socket: an experimental study in the dog.," Int. J. Periodontics Restorative Dent., vol. 28, no. 2, pp. 123-135, 2008.

6. H. L. Wang, K. Kiyonobu, and R. F. Neiva, "Socket augmentation: rationale and technique," Implant Dent, vol. 13, no. 4, pp. 286-296, 2004.

7. M. G. Araujo and J. Lindhe, "Socket grafting with the use of autologous bone: an experimental study in the dog.," Clin. Oral Implants Res., vol. 22, no. 1, pp. 9-13, 2011.

8. M. G. Araújo, B. Liljenberg, and J. Lindhe, "Dynamics of Bio-Oss ${ }^{\circledR}$ Collagen incorporation in fresh extraction wounds: An experimental study in the dog," Clin. Oral Implants Res., vol. 21, no. 1, pp. 55-64, 2010.

9. W. Becker, B. E. Becker, and R. Caffesse, "A comparison of demineralized freeze-dried bone and autologous bone to induce bone formation in human extraction sockets.," J. Periodontol., vol. 65, pp. 1128-1133, 1994.

10. J. M. Iasella et al., "Ridge Preservation with Freeze-Dried Bone Allograft and a Collagen
Membrane Compared to Extraction Alone for Implant Site Development: A Clinical and Histologic Study in Humans," J. Periodontol., vol. 74, no. 7, pp. 990-999, Jul. 2003.

11. N. E. Carlson and R. B. Roach, "Platelet-rich plasma: clinical applications in dentistry.," J. Am. Dent. Assoc., vol. 133, no. 10, pp. 1383-6, Oct. 2002.

12. R. Gruber, F. Varga, M. B. Fischer, and G. Watzek, "Platelets stimulate proliferation of bone cells: involvement of platelet-derived growth factor, microparticles and membranes.," Clin. Oral Implants Res., vol. 13, no. 5, pp. 529-35, Oct. 2002.

13. G. Weibrich, S. H. Gnoth, M. Otto, T. E. Reichert, and W. Wagner, "[Growth stimulation of human osteoblast-like cells by thrombocyte concentrates in vitro].," Mund. Kiefer. Gesichtschir., vol. 6, no. 3, pp. 168-74, May 2002.

14. G. Intini, "The use of platelet-rich plasma in bone reconstruction therapy.," Biomaterials, vol. 30, no. 28, pp. 4956-66, Oct. 2009.

15. C. H. F. Hämmerle, M. G. Araújo, and M. Simion, "Evidence-based knowledge on the biology and treatment of extraction sockets," Clin. Oral Implants Res., vol. 23, no. SUPPL. 5, pp. 80-82, 2012.

16. F. Vignoletti, P. Matesanz, D. Rodrigo, E. Figuero, C. Martin, and M. Sanz, "Surgical protocols for ridge preservation after tooth extraction. A systematic review," Clin. Oral Implants Res., vol. 23, no. SUPPL. 5, pp. 22-38, 2012.

17. M. A. Atieh, N. H. Alsabeeha, A. G. Payne, W. Duncan, C. M. Faggion, and M. Esposito, "Interventions for replacing missing teeth: alveolar ridge preservation techniques for dental implant site development.," Cochrane database Syst. Rev., vol. 5, p. CD010176, 2015.

18. A. Temmerman et al., "The use of leucocyte and platelet-rich fibrin in socket management and ridge preservation: a split-mouth, randomized, controlled clinical trial," J. Clin. Periodontol., vol. 43, no. 11, pp. 990-999, Nov. 2016.

19. S. Srisurang, B. Kantheera, L. Narit, and P. Prisana, "Socket preservation using platelet-rich fibrin in conjunction with epithelialized palatal free graft in minipigs," J. Oral Maxillofac. Surgery, Med. Pathol., vol. 26, no. 2, pp. 108-117, 2014. 
20. S. Jambhekar, F. Kernen, and A. S. Bidra, "Clinical and histologic outcomes of socket grafting after flapless tooth extraction: a systematic review of randomized controlled clinical trials.," J. Prosthet. Dent., vol. 113, no. 5, pp. 371-82, May 2015.

21. A. Barone, N. N. Aldini, M. Fini, R. Giardino, J. L. Calvo Guirado, and U. Covani, "Xenograft versus extraction alone for ridge preservation after tooth removal: a clinical and histomorphometric study.," J. Periodontol., vol. 79, no. 8, pp. 1370-7, 2008.

22. J. M. Iasella et al., "Ridge preservation with freeze-dried bone allograft and a collagen membrane compared to extraction alone for implant site development: a clinical and histologic study in humans.," J. Periodontol., vol. 74, no. 7, pp. 990-9, 2003.

23. W. Becker, C. Clokie, L. Sennerby, M. R. Urist, and B. E. Becker, "Histologic findings after implantation and evaluation of different grafting materials and titanium micro screws into extraction sockets: case reports.," J. Periodontol., vol. 69, no. 4, pp. 414-21, 1998.

24. D. BUSER, B. HOFFMANN, J. . BERNARD, A. LUSSI, D. METTLER, and R. K. SCHENK, "Evaluation of bone filling materials in membrane-protected defects of the mandible. A histomorphometric study in miniature pigs.," Clini Oral Impl Res, vol. 9, no. 3, pp. 137-150, 1998.

25. M. Araújo, E. Linder, and J. Lindhe, "Effect of a xenograft on early bone formation in extraction sockets: An experimental study in dog," Clin. Oral Implants Res., vol. 20, no. 1, pp. 1-6, 2009.

26. D. Carmagnola, P. Adriaens, and T. Berglundh, "Healing of human extraction sockets filled with Bio-Oss.," Clin. Oral Implants Res., vol. 14, no. 2, pp. 137-143, 2003.

27. L. Molly, H. Vandromme, M. Quirynen, E. Schepers, J. L. Adams, and D. van Steenberghe, "Bone formation following implantation of bone biomaterials into extraction sites.," J. Periodontol., vol. 79, no. 6, pp. 1108-1115, 2008.

28. D. M. Dohan et al., "Platelet-rich fibrin (PRF): a second-generation platelet concentrate. Part I: technological concepts and evolution.," Oral Surg. Oral Med. Oral Pathol. Oral Radiol. Endod., vol. 101, no. 3, pp. e3744-, Mar. 2006.
29. A. R. Pradeep, N. S. Rao, E. Agarwal, P. Bajaj, M. Kumari, and S. B. Naik, "Comparative evaluation of autologous platelet-rich fibrin and platelet-rich plasma in the treatment of 3-wall intrabony defects in chronic periodontitis: a randomized controlled clinical trial.," J. Periodontol., vol. 83, no. 12, pp. 1499-507, Dec. 2012.

30. A. Temmerman et al., "The use of leucocyte and platelet-rich fibrin in socket management and ridge preservation: a split-mouth, randomized, controlled clinical trial.," J. Clin. Periodontol., vol. 43, no. 11, pp. 990-999, Nov. 2016.

31. F. Hauser, N. Gaydarov, I. Badoud, L. Vazquez, J.-P. Bernard, and P. Ammann, "Clinical and histological evaluation of postextraction plateletrich fibrin socket filling: a prospective randomized controlled study.," Implant Dent., vol. 22, no. 3, pp. 295-303, Jun. 2013.

32. Z. Mazor, R. A. Horowitz, M. Del Corso, H. S. Prasad, M. D. Rohrer, and D. M. Dohan Ehrenfest, "Sinus floor augmentation with simultaneous implant placement using Choukroun's plateletrich fibrin as the sole grafting material: a radiologic and histologic study at 6 months.," J. Periodontol., vol. 80, no. 12, pp. 2056-64, Dec. 2009.

33. M. Toffler et al., "Introducing Choukroun's Platelet Rich Fibrin (PRF) to the Reconstructive Surgery Milieu.,”Jan. 2009.

34. A. Simonpieri, J. Choukroun, M. Del Corso, G. Sammartino, and D. M. Dohan Ehrenfest, "Simultaneous sinus-lift and implantation using microthreaded implants and leukocyte- and platelet-rich fibrin as sole grafting material: a sixyear experience.," Implant Dent., vol. 20, no. 1, pp. 2-12, Feb. 2011.

35. S. Suttapreyasri and N. Leepong, "Influence of platelet-rich fibrin on alveolar ridge preservation.," J. Craniofac. Surg., vol. 24, no. 4, pp. 1088-94, Jul. 2013.

36. Y. Zhang, S. Tangl, C. D. Huber, Y. Lin, L. Qiu, and X. Rausch-Fan, "Effects of Choukroun's plateletrich fibrin on bone regeneration in combination with deproteinized bovine bone mineral in maxillary sinus augmentation: a histological and histomorphometric study.," J. Craniomaxillofac. Surg., vol. 40, no. 4, pp. 321-8, Jun. 2012. 
37. M. Del Fabbro, S. Corbella, S. Taschieri, L. Francetti, and R. Weinstein, "Autologous platelet concentrate for post-extraction socket healing: a systematic review.," Eur. J. Oral Implantol., vol. 7, no. 4, pp. 333-44, 2014.

38. M. Del Fabbro, M. Bortolin, and S. Taschieri, "Is autologous platelet concentrate beneficial for postextraction socket healing? A systematic review," Int. J. Oral Maxillofac. Surg., vol. 40, no. 9, pp. 891-900, Sep. 2011.

39. W. L. Tan, T. L. T. Wong, M. C. M. Wong, and N. P. Lang, "A systematic review of post-extractional alveolar hard and soft tissue dimensional changes in humans.," Clin. Oral Implants Res., vol. 23 Suppl 5, pp. 1-21, 2012.

40. N. Mardas, V. Chadha, and N. Donos, "Alveolar ridge preservation with guided bone regeneration and a synthetic bone substitute or a bovine-derived xenograft: A randomized, controlled clinical trial," Clin. Oral Implants Res., vol. 21, no. 7, pp. 688698, 2010.

41. V. M. Festa, F. Addabbo, L. Laino, F. Femiano, and R. Rullo, "Porcine-Derived Xenograft Combined with a Soft Cortical Membrane versus Extraction Alone for Implant Site Development: A Clinical Study in Humans," Clin. Implant Dent. Relat. Res., vol. 15, no. 5, pp. 707-713, 2013.

42. R. E. Jung et al., "Radiographic evaluation of different techniques for ridge preservation after tooth extraction: a randomized controlled clinical trial.," J. Clin. Periodontol., vol. 40, no. 1, pp. 908, Jan. 2013.

43. A. Barone, N. N. Aldini, M. Fini, R. Giardino, J. L. Calvo Guirado, and U. Covani, "Xenograft versus extraction alone for ridge preservation after tooth removal: a clinical and histomorphometric study.," J. Periodontol., vol. 79, no. 8, pp. 1370-7, Aug. 2008.

44. S. Suttapreyasri and N. Leepong, "Influence of platelet-rich fibrin on alveolar ridge preservation.," J. Craniofac. Surg., vol. 24, no. 4, pp. 1088-94, Jul. 2013.

45. C. E. Nemcovsky and V. Serfaty, "Alveolar ridge preservation following extraction of maxillary anterior teeth. Report on 23 consecutive cases.," J. Periodontol., vol. 67, no. 4, pp. 390-5, 1996.

46. P. Mercier, "Ridge reconstruction with hydroxylapatite. Part 1. Anatomy of the residual ridge.," Oral Surg. Oral Med. Oral Pathol., vol. 65, no. 5, pp. 505-10, 1988.

47. D. Buser, W. Martin, and U. C. Belser, "Optimizing esthetics for implant restorations in the anterior maxilla: anatomic and surgical considerations.," Int. J. Oral Maxillofac. Implants, vol. 19 Suppl, pp. 43-61, 2004.

48. V. Lekovic et al., "A bone regenerative approach to alveolar ridge maintenance following tooth extraction. Report of 10 cases.," J. Periodontol., vol. 68, no. 6, pp. 563-570, 1997.

49. V. M. Festa, F. Addabbo, L. Laino, F. Femiano, and R. Rullo, "Porcine-Derived Xenograft Combined with a Soft Cortical Membrane versus Extraction Alone for Implant Site Development: A Clinical Study in Humans," Clin. Implant Dent. Relat. Res., p. no-no, Dec. 2011.

50. A. Barone, M. Ricci, P. Tonelli, S. Santini, and U. Covani, "Tissue changes of extraction sockets in humans: a comparison of spontaneous healing vs. ridge preservation with secondary soft tissue healing," Clin. Oral Implants Res., p. n/a-n/a, Jul. 2012.

51. J. Cosyn, R. Cleymaet, and H. De Bruyn, "Predictors of Alveolar Process Remodeling Following Ridge Preservation in High-Risk Patients," Clin. Implant Dent. Relat. Res., vol. 18, no. 2, pp. 226-233, Apr. 2016.

52. L. P. Maia et al., "Influence of Periodontal Biotype on Buccal Bone Remodeling after Tooth Extraction Using the Flapless Approach with a Xenograft: A Histomorphometric and Fluorescence Study in Small Dogs," Clin. Implant Dent. Relat. Res., vol. 17, pp. e221-e235, Jan. 2015.

53. S. Spinato, P. Galindo-Moreno, D. Zaffe, F. Bernardello, and C. M. Soardi, "Is socket healing conditioned by buccal plate thickness? A clinical and histologic study 4 months after mineralized human bone allografting," Clin. Oral Implants Res., vol. 25, no. 2, pp. e120-e126, Feb. 2014. 